\title{
Radioisotope Renography as a Renal Function Test in the Newborn
}

\author{
B. L. KATHEL \\ From the Department of Urology, Alder Hey Children's Hospital; and Institute of Child Health, University of Liverpool Cు
}

\begin{abstract}
Kathe1, B. L. (1971). Archives of Disease in Childhood, 46, 314. Radioisotope renography as a renal function test in the newborn. Isotope renography has been carried out in 32 babies with neurogenic bladder due to spina bifida or with other urological lesions. The tracings can be interpreted according to the standards applicable to renography in older children. Comparison of renography and intravenous urography showed a close correlation between the two tests, but renography proved to be more sensitive and informative.

As renography is easily performed and since the radiation dosage is very small, it is of value in those patients where frequent assessment of the function and emptying capability of each individual kidney is required.
\end{abstract}

A large amount of work has been done concerning isotope renography as a test of renal function in adults, but relatively little has been recorded about the value of the technique in infancy. The normal renogram tracing shows three phases. First, there is a sudden rise in radioactivity, then a slow rise to a peak (second phase) and subsequently a fall away (third phase) (Fig. 1). From this department, Johnston and Irving (1967) described renogram tracings from normal kidneys in children under 2 years of age. These they found to be relatively flat as compared with those obtained from older children. Winter et al. (1968) on the other hand performed renography in 26 newborn babies with presumed normal kidney function, and found that in 19 the tracings were of normal adult type; 7 showed a prolonged functional and/or excretory phase.

The present contribution relates to infants under the age of 2 months. It is concerned with the analysis of renograms from kidneys with normal and abnormal function, and with the rates of elimination of radioisotope from the blood and of its accumulation in the bladder. The results are compared with the findings on intravenous pyelography and with biochemical studies. The main object of this presentation is to evaluate the test as an index of individual renal function in the newborn.

Received 14 October 1970

\section{Technique}

Lugol's iodine solution $(0.2 \mathrm{ml})(17 \cdot 3 \mathrm{mg}$ total iodine and $6.6 \mathrm{mg}$ free iodine) is given orally on the night before and on the evening after the test in order to block the possible uptake of any free radioactive iodine by the thyroid. Renography is carried out $1 \frac{1}{2}$ hours $\propto$ after a feed to obtain a standard level of hydration. The $\vec{\overrightarrow{ }}$ patient is bandaged to a crucifix splint in the prone $\frac{3}{3}$ position, a detector probe is placed over the site of each kidney, and a third is positioned over the left scapular region. The probes are connected to ratemeters and recorders. The meter range employed has been $30 \%$ and the paper speed $1.25 \mathrm{~cm} /$ minute. Hippuran? ${ }^{125} \mathrm{I} 0.3 \mu \mathrm{Ci} / \mathrm{kg}$ is injected rapidly into a scalp vein. For renography in children over 2 years of age we use a dose of $0.25 \mu \mathrm{Ci} / \mathrm{kg}$ and a meter range of 100 . The modification in technique for newborn infants is necessary to obtain sufficient amplitude in the tracing. If $ᄋ$ necessary, the positions of the kidney probes are readjusted within a few seconds of the start of the test in order to obtain maximum deflection. The renogram tracings last from 10 to 30 minutes. At the conclusion $N$ bladder radioactivity is recorded with the baby in the supine position. All recordings reproduced by recorders 0 are from right to left-a convention in the renographic $\underset{\omega}{\omega}$ field.

The following parameters were measured from renogram curves. (1) The time interval from the injection to the peak of the tracing (Tm). (2) The time interval of from the injection to the point where the curve decays ? to $50 \%$ of the maximum $\left(\mathrm{T}_{2}\right)$. (3) The amplitude of $-\overline{0}$ tracing is expressed by radioactive counts per second.

The parameters were compared with those obtained 


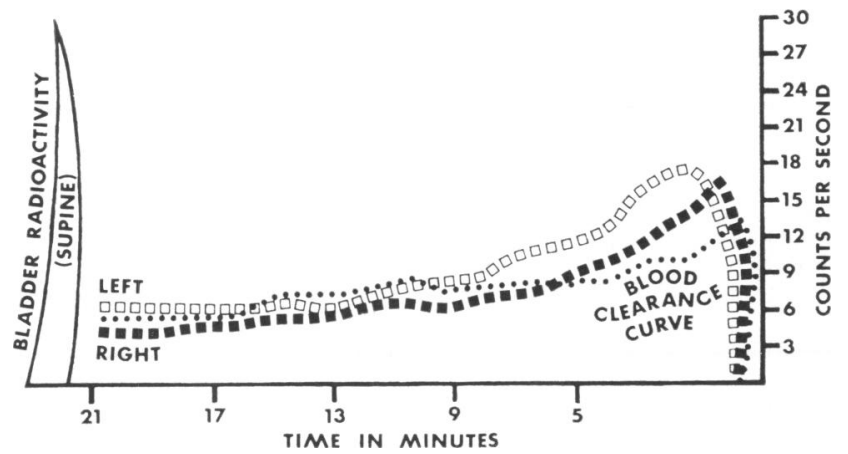

FIG. 1.-Normal left and right renograms, blood clearance curve, and bladder radioactivity recorded on 12 th day of life. Slow clearance of tracer is shown. (This recording and those in Fig. 2, 3b, 4a and c, and 5a are to be read from right to left.) These have been rescaled in time from the originals to a paper speed of $0.6 \mathrm{~cm} / \mathrm{min}$ in order to facilitate publication.

from kidneys in children over 2 years of age. In the latter group, from our observations of 80 normal renograms, the normal range of $\mathrm{Tm}$ is from 2.5 to 5.5 minutes, with an average of 4 minutes and the normal range of $T \frac{1}{2}$ is from 8.2 to 19.9 minutes, with an average of 14.0 minutes. The neonatal renograms were classified as normal, if within these limits, and abnormal if outside the limits.

\section{Material}

Two groups of patients were studied.

(1) 27 newborn infants with neurogenic bladder due to spina bifida. In these, intravenous pyelography was carried out within 12 days of birth. In 19 patients, radiology was performed before renography and in 8 patients afterwards. Renography was carried out between the 9 th and 30 th days of life.

(2) 5 patients with urinary tract disorders without spina bifida. In these, renography was carried out between the 30 th and 60 th days.

The weights of the patients in both groups varied from $2 \cdot 5 \mathrm{~kg}$ to $4 \cdot 5 \mathrm{~kg}$.

\section{Results}

Normal kidneys. The renograms from 41 kidneys of normal pyelographic appearance from Groups 1 and 2 were assessed. In 17 of these, parameters $\mathrm{Tm}$ and $\mathrm{T} \frac{1}{2}$ both corresponded with our accepted normal standards (Fig. 1). In 20, a peak was not defined, therefore $\mathrm{Tm}$ was not measurable; in these, $T_{\frac{1}{2}}$ was normal in 3, prolonged in 9 , and not measurable in 8 . In 4 instances both $\mathrm{Tm}$ and $\mathrm{T}_{\frac{1}{2}}$ were prolonged. In the entire group $T m$ or $T \frac{1}{2}$ were prolonged either singly or together in 13 instances. The details of range and average of parameters in minutes are shown in Tables I and II.
TABLE I

Analysis of 41 Renograms from Pyelographically Normal Kidneys

\begin{tabular}{|c|c|c|}
\hline & $\operatorname{Tm}(\min )$ & $T_{\frac{1}{2}}(\min )$ \\
\hline $\begin{array}{l}17 \text { Normal range } \\
4 \text { Prolonged } \\
20 \text { Peaks not } \\
\text { defined }\end{array}$ & $\begin{array}{l}1 \text { to } 5 \cdot 5 \text {, average } 3 \cdot 2 \\
5 \cdot 75 \text { to } 8 \text {, average } \\
6 \cdot 8\end{array}$ & 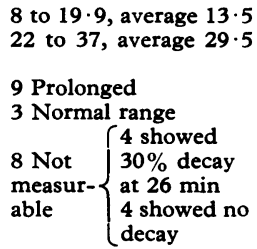 \\
\hline
\end{tabular}

TABLE II

Detailed analysis of 17 Normal Renograms from Pyelographically Normal Kidneys

\begin{tabular}{|c|c|}
\hline $\operatorname{Tm}(\min )$ & $\mathrm{T}_{\frac{1}{2}}(\mathrm{~min})$ \\
\hline $\begin{array}{l}2 \cdot 65 \\
2 \cdot 84 \\
3 \cdot 0 \\
2 \cdot 5 \\
2 \cdot 5 \\
2 \cdot 75 \\
4 \cdot 6 \\
4 \cdot 5 \\
4 \cdot 75 \\
5 \cdot 5 \\
2 \cdot 3 \\
3 \cdot 0 \\
3 \cdot 0 \\
2 \cdot 5 \\
5 \cdot 15 \\
3 \cdot 0 \\
1 \cdot 25\end{array}$ & $\begin{array}{l}10 \cdot 4 \\
10 \cdot 4 \\
13 \cdot 0 \\
11 \cdot 0 \\
11 \cdot 0 \\
16 \cdot 75 \\
12 \cdot 5 \\
12 \cdot 0 \\
14 \cdot 6 \\
14 \cdot 6 \\
12 \cdot 25 \\
10 \cdot 75 \\
13 \cdot 0 \\
16 \cdot 5 \\
18 \cdot 75 \\
19 \cdot 9 \\
8 \cdot 0\end{array}$ \\
\hline
\end{tabular}

Weights of the patients varied from $2.5 \mathrm{~kg}$ to $4.5 \mathrm{~kg}$. Renography was carried out between 9th and 60th days of life. 
TABLE III

Correlation Between Renograms and Intravenous Pyelograms

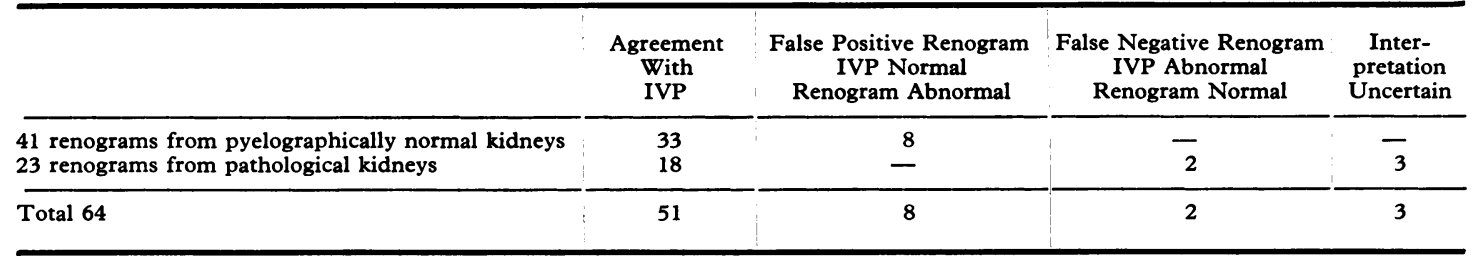

Bladder radioactivity in 33 renograms was within the normal range of 20 to 30 c.p.s. with an average of 25 c.p.s. (Fig. 1). In 8 renograms the range was from 3 to 15 c.p.s.; these were from the group in which the third phase was level or was slowly decaying.

41 comparisons of renograms and normal pyelograms were studied (Table III). The renograms and intravenous pyelograms corresponded in 33 normal kidneys and did not in 8 . In the latter, the renogram showed delayed decay or a level third phase. These 4 patients were spina bifida babies with a raised blood urea and a distended and inexpressible bladder, suggesting urinary stasis even though the upper urinary tract was undilated on pyelography.

Pathological kidneys. The renograms of 23 abnormal kidneys from Groups 1 and 2 were studied. Of these, 21 were hydronephrotic, 1 was multicystic, and 1 was congenitally dysplastic. 4 renograms relating to the multicystic kidney, the congenitally dysplastic kidney, and 2 of the hydronephrotic kidneys corresponded to the blood background, signifying no renal function. In the remaining 19 renograms, the third phase was level after the maximum in 7 , rising in 5 , and there was only $30 \%$ decay at 26 minutes in 7 .

The bladder radioactivity ranged from 18 to 30 c.p.s. with an average of 24 c.p.s. in cases of unilateral pathology. With bilateral hydronephrosis the range was from 3 to 12 c.p.s. with an average of $7 \cdot 5$ c.p.s.

23 comparisons of renograms and pyelograms of abnormal kidneys were studied (Table III). In 18, the renographic and pyelographic findings corresponded. In 2 the renograms were normal but the pyelograms showed minor dilatation of the calyces. In the remaining 3 the interpretation was difficult as it was not clear whether the tracing represented blood background radioactivity or whether there was in addition very subnormal renal function.

\section{Discussion}

It has long been realized that kidney function in the neonate differs from that in the older child and the adult. This is probably due mainly to anatomical and physiological differences between the age groups. In the newborn, the proximal convoluted tubules are still of primitive form and the loops of Henle are short (Smith, 1951). In addition the cuboidal epithelium lining the glomerular capsule which is present in the fetus, may persist until 2 years of age. In the newborn, the arterial blood pressure and, by presumption, the intraglomerular pressure are relatively low. Both glomerular and tubular functions are affected. The glomerular filtration rate in the neonate is low (Barnett, 1940), though the precise measurements depend upon whether calculation is related to surface area or to total body water. Edelmann and Spitzer (1969) summarize that low glomerular filtration rates (GFR) in the neonatal period are due to incomplete morphological and functional development of all components involved in the process of filtration. This low GFR limits the capacity of the infant to withstand stress of loading. An adult level of GFR is reached at the age of 9 to 12 months. Grotte, Arturson, and Malmberg (1968) believe that glomerular permeability increases with the development of the nephron. With increasing age, the pore radius of the glomerular membrane, approximately $20 \AA$ in the neonatal period, increases to $40 \AA$ in the adult. The defect in tubular function in the newborn is shown by the $30 \%$ reduction in extraction of PAH as compared with the adult, by the reduction in the effective renal plasma flow as indicated by diodrast or PAH clearances, and by the inability of the newborn kidney to produce a concentrated urine. Calcagno and Rubin (1963) demonstrated that this was not due to a reduction in renal perfusion, which supports the concept of a functionally limited cortex. Our own observations of slow clearance of Hippuran 125I from the blood (Fig. 1) favour the above concept. McCance (1948) pointed out that, while 


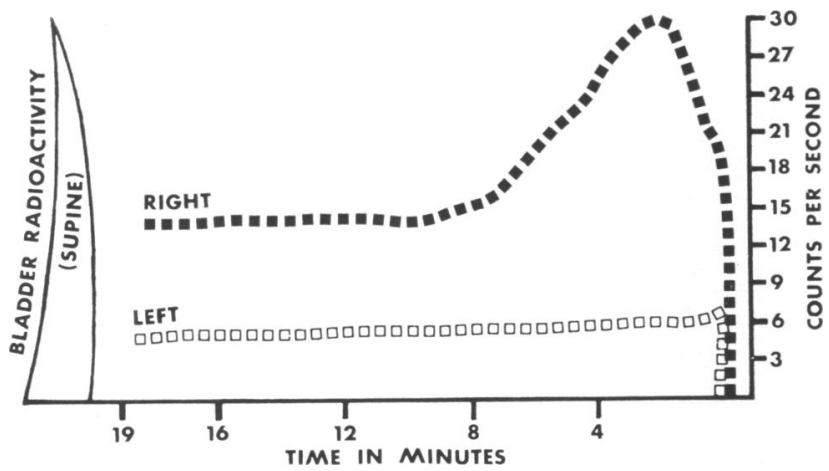

FIG. 2.-Renograms recorded on 30th day of life in baby with an afunctional left multicystic kidney. Normal right renogram. Flat tracing on left.

kidney function is adequate to maintain homeostasis in the normal infant, the kidney has little reserve capacity and may be unable to compensate for disturbances in metabolism or water balance.

In 17 of the renogram tracings obtained from 41 pyelographically normal kidneys in the newborn, the parameters $\mathrm{Tm}$ and $T \frac{1}{2}$ were within the range of normality for older children (Tables I and II). Winter et al. (1968) had a similar correspondence in 19 of 26 neonatal cases. However in 14 normal neonatal kidneys in our series, $\mathrm{Tm}$ and/or $\mathrm{T} \frac{1}{2}$ were prolonged as compared with tracings from older children. Again Winter et al. (1968) had similar findings in 7 of 26 neonatal cases. In 20 of our tracings from normal kidneys, measurement of Tm was not possible, since a clear peak at the end of the second phase was not defined. Winter et al. (1968) did not have this difficulty, probably because he used a much slower paper speed. When $T m$ and $T \frac{1}{2}$ are prolonged or when $T m$ cannot be measured, we believe that the level of bladder radioactivity is relevant in the interpretation of renal function. If bladder radioactivity is within the range of 20 to 30 c.p.s. the overall renal function can be assumed to be normal. On the other hand, if bladder radioactivity is below 15 c.p.s. renal function can be interpreted as subnormal provided there is no obstruction in the upper urinary tract. We have not found the blood clearance curve of tracer to be helpful as an index of renal function in the newborn since the clearance is much slower than in older children (Fig. 1).

Our recent renogram tracings from newborn infants differ from those obtained by Johnston and Irving (1967). These authors noted a flat or subnormal tracing to be an invariable occurrence in children under the age of 2 years. The reason for the different finding is not clear. Johnston and Irving were, however, using Hippuran 131I and the babies were examined in the supine position which may make correct positioning of the large ${ }^{131}$ I probes difficult.

In the pyelographically abnormal kidneys from Groups 1 and 2, 19 hydronephrotic as a result of obstruction of varying pathogenesis, renography showed that the third phase was rising in 5 , was level at the maximum in 7 , and in the remaining 7 there was only $30 \%$ decay at 26 minutes. In 4 kidneys, where there was no concentration on pyelography, 1 being congenitally dysplastic, 1 multicystic, and 2 hydronephrotic, the tracings were entirely flat (Fig. 2).

64 comparisons between renography and pyelography were made; 51 renograms correlated closely with the findings on intravenous pyelography (Table III). False positive renograms, where the pyelogram was normal but the parameters of the renogram tracing were outside the accepted limits, occurred in 8 kidneys in 4 patients. These 4 babies were ill, the blood urea was raised and bladder was distended and inexpressible (Fig. 3 a and b), suggesting that renography was a better index of renal function and evacuation than pyelography. The greater prognostic value of renography as compared with pyelography was shown in the case illustrated in Fig. 4. This spina bifida baby also had a tensely distended bladder. An intravenous pyelogram at the age of 28 days showed no upper tract dilatation, but the renogram (Fig. 4a) showed some delay in the third phase on the left side. At the age of 8 months intravenous urography showed well-marked left hydronephrosis and hydroureter (Fig. 4b), and at this 

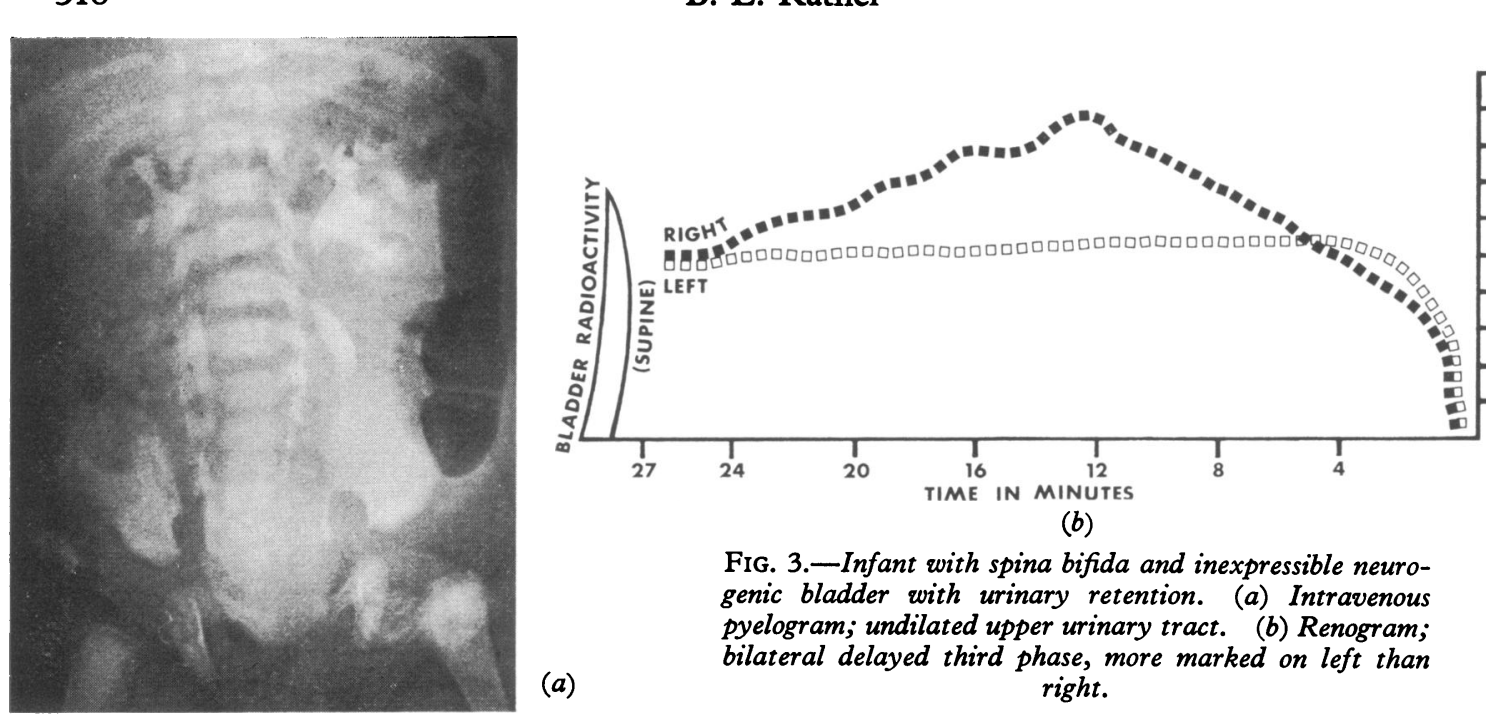

(b)

FIG. 3.-Infant with spina bifida and inexpressible neurogenic bladder with urinary retention. (a) Intravenous pyelogram; undilated upper urinary tract. (b) Renogram; bilateral delayed third phase, more marked on left than

(a) right.

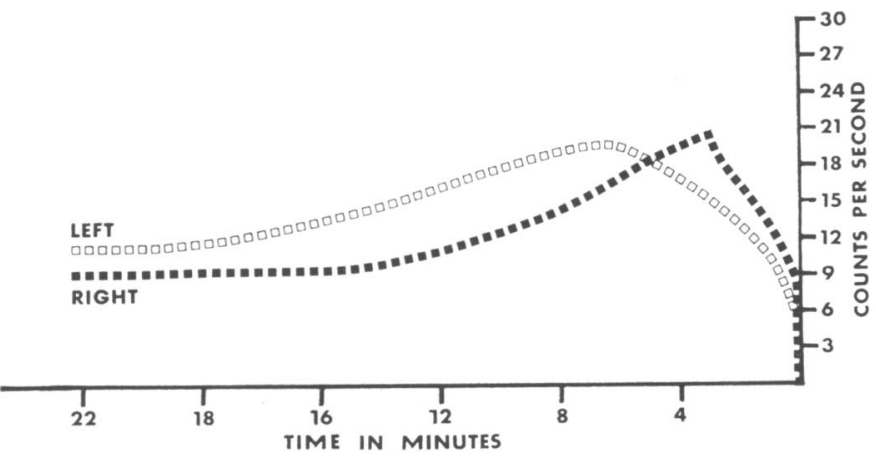

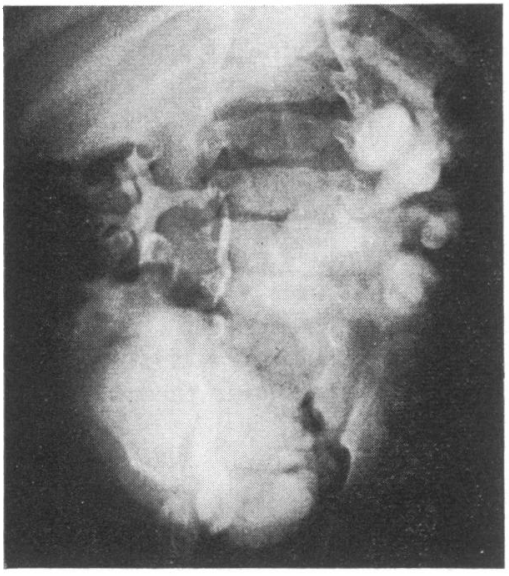

(b)

(a)

FIG. 4.-Prognostic significance of renography. Infant with neurogenic bladder due to spina bifida. (a) Renogram on 28 th day of life; some delay in emptying on left side; at this time the intravenous pyelogram was normal. (b) Intravenous pyelogram, aged 8 months; marked left hydronephrosis and hydroureter. (c) Renogram aged 8 months; severe stasis on left side. 

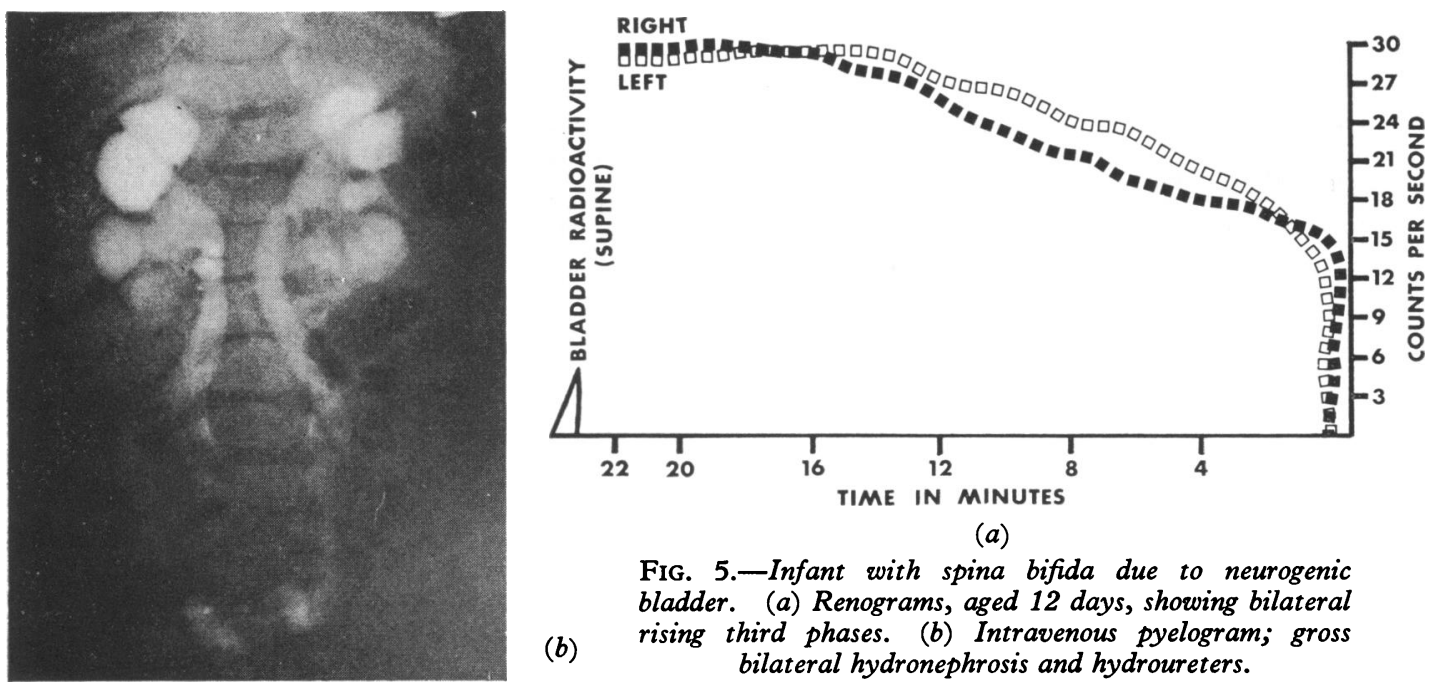

(a)

FIG. 5.-Infant with spina bifida due to neurogenic bladder. (a) Renograms, aged 12 days, showing bilateral rising third phases. (b) Intravenous pyelogram; gross bilateral hydronephrosis and hydroureters.

time the renogram was typical of severe upper tract stasis (Fig. 4c).

The correlation between pyelography and renography was much closer with pathological kidneys. The renogram tracings were normal in only 2 of the 23 pathological kidneys; each of these showed only a mild degree of hydronephrosis on pyelography. The behaviour of the third phase of the renogram corresponded closely with the degree of pelvicalyceal dilatation. Severe dilatation was associated with a rising third phase (Fig. $5 \mathrm{a}$ and b), moderate dilatation with a third phase parallel to the baseline, and mild dilatation with a delayed third phase. In 8 patients renography was carried out before intravenous pyelography and the expectations were confirmed. On the whole, renography correlated very well with intravenous pyelography.

Intravenous pyelography has been the principal diagnostic test of individual kidney function in the newborn as with older age groups. The test allows visualization of anatomical details, but does not measure renal function since it is influenced by the state of hydration of the patient and by the concentration and the volume of contrast medium employed. Relating radiological opacity with renal function is not valid with modern contrast media and techniques. In addition the results may be inconclusive because of bowel contents obscuring the kidney on the radiograph. Isotope renography gives a qualitative index of the tubular function and emptying capability of the individual kidney. The correlation with pyelography in the detection of renal pathology is close. There is no special preparation required and the results are obtained quickly. It is a more sensitive test than pyelography. Renograms in the newborn can be interpreted by applying the standards from children over 2 years of age. The radiation dose with renography is only about $1 / 5000$ of that required for a single $x$-ray exposure (Winter, 1963). The test can, therefore, be safely and conveniently repeated in following the progress of renal function over a lengthy period of time.

The great value of renography lies, in our view, in the follow-up of children who will require repeated and fairly frequent assessment of the function and drainage capability of each individual kidney. As such it can be of great use in the management and care of the child with neurogenic bladder due to spina bifida.

I am grateful to Mr. J. H. Johnston for his encouragement and advice in the preparation of this report.

\section{REFERENCES}

Barnett, H. L. (1940). Renal physiology in infants and children. I. Method for estimation of glomerular filtration rate. Proceedings of the Society for Experimental Biology and Medicine, 44, 654.

Calcagno, P. L., and Rubin, M. I. (1963). Renal extraction of paraaminohippurate in infants and children. Fournal of Clinical Investigation, 42, 1632.

Edelmann, C. M., Jr., and Spitzer, A. (1969). The maturing kidney: a modern view of well-balanced infants with imbalanced nephrons. Fournal of Pediatrics, 75, 509.

Grotte, G., Arturson, G., and Malmberg, P. (1968). Maturation of kidney function. Proceedings of the XIIth International Congress of Pediatrics, Mexico, 3, 32 . 
Johnston, J. H., and Irving, I. M. (1967). Experiences with radioisotope renography in children. Archives of Disease in Childhood, $42,583$.

McCance, R. A. (1948). Renal function in early life. Physiological Review, 28, 331 .

Smith, H. W. (1951). The Kidney: Structure and Function in Health and Disease, p. 265. Oxford University Press, New York.

Winter, C. C. (1963). Radioisotope Renography: A Kidney Function Test Performed with Radioisotope-Labeled Agents. Williams and Wilkins, Baltimore.
Winter, C. C., Elliott, J., Grace, D., and Robertson, A. (1968). Radioisotoperenography in the assessment of renal function in the newborn. fournal of Urology, 100, 99.

Correspondence to Mr. B. L. Kathel, Department of Urology, Alder Hey Children's Hospital, Eaton Road, Liverpool L12 2AP. 